\title{
Functional MRI for radiotherapy dose painting
}

Citation for published version (APA):

van der Heide, U. A., Houweling, A. C., Groenendaal, G., Beets-Tan, R. G. H., \& Lambin, P. (2012). Functional MRI for radiotherapy dose painting. Magnetic Resonance Imaging, 30(9), 1216-1223. https://doi.org/10.1016/j.mri.2012.04.010

Document status and date:

Published: 01/11/2012

DOI:

10.1016/j.mri.2012.04.010

Document Version:

Publisher's PDF, also known as Version of record

Document license:

Taverne

\section{Please check the document version of this publication:}

- A submitted manuscript is the version of the article upon submission and before peer-review. There can be important differences between the submitted version and the official published version of record.

People interested in the research are advised to contact the author for the final version of the publication, or visit the DOI to the publisher's website.

- The final author version and the galley proof are versions of the publication after peer review.

- The final published version features the final layout of the paper including the volume, issue and page numbers.

Link to publication

\footnotetext{
General rights rights.

- You may freely distribute the URL identifying the publication in the public portal. please follow below link for the End User Agreement:

www.umlib.nl/taverne-license

Take down policy

If you believe that this document breaches copyright please contact us at:

repository@maastrichtuniversity.nl

providing details and we will investigate your claim.
}

Copyright and moral rights for the publications made accessible in the public portal are retained by the authors and/or other copyright owners and it is a condition of accessing publications that users recognise and abide by the legal requirements associated with these

- Users may download and print one copy of any publication from the public portal for the purpose of private study or research.

- You may not further distribute the material or use it for any profit-making activity or commercial gain

If the publication is distributed under the terms of Article $25 \mathrm{fa}$ of the Dutch Copyright Act, indicated by the "Taverne" license above, 


\title{
Functional MRI for radiotherapy dose painting
}

\author{
Uulke A. van der Heide ${ }^{a, *}$, Antonetta C. Houweling ${ }^{a}$, Greetje Groenendaal ${ }^{a}$, \\ Regina G.H. Beets-Tan ${ }^{\mathrm{b}}$, Philippe Lambin ${ }^{\mathrm{c}}$ \\ ${ }^{a}$ Department of Radiation Oncology, Netherlands Cancer Institute, Antoni van Leeuwenhoek Hospital, 1066 CX Amsterdam, the Netherlands \\ ${ }^{\mathrm{b}}$ Department of Radiology, GROW-School for Oncology, Maastricht University Medical Center, Maastricht, the Netherlands \\ ${ }^{\mathrm{c}}$ Department of Radiation Oncology (MAASTRO), GROW-School for Oncology, Maastricht University Medical Center, Maastricht, the Netherlands \\ Received 5 February 2012; revised 26 March 2012; accepted 1 April 2012
}

\begin{abstract}
Modern radiation therapy techniques are exceptionally flexible in the deposition of radiation dose in a target volume. Complex distributions of dose can be delivered reliably, so that the tumor is exposed to a high dose, whereas nearby healthy structures can be avoided. As a result, an increase in curative dose is no longer invariably associated with an increased level of toxicity. This modern technology can be exploited further by modulating the required dose in space so as to match the variation in radiation sensitivity in the tumor. This approach is called dose painting.

For dose painting to be effective, functional imaging techniques are essential to identify regions in a tumor that require a higher dose. Several techniques are available in nuclear medicine and radiology. In recent years, there has been a considerable research effort concerning the integration of magnetic resonance imaging (MRI) into the external radiotherapy workflow motivated by the superior soft tissue contrast as compared to computed tomography. In MRI, diffusion-weighted MRI reflects the cell density of tissue and thus may indicate regions with a higher tumor load. Dynamic contrast-enhanced MRI reflects permeability of the microvasculature and blood flow, correlated to the oxygenation of the tumor. These properties have impact on its radiation sensitivity.

New questions must be addressed when these techniques are applied in radiation therapy: scanning in treatment position requires alternative solutions to the standard patient setup in the choice of receive coils compared to a diagnostic department. This standard positioning also facilitates repeated imaging. The geometrical accuracy of MR images is critical for high-precision radiotherapy. In particular, when multiparametric functional data are used for dose painting, quantification of functional parameters at a high spatial resolution becomes important.

In this review, we will address these issues and describe clinical developments in MRI-guided dose painting.
\end{abstract} (C) 2012 Elsevier Inc. All rights reserved.

Keywords: DCE-MRI; DWI; Radiation oncology; Dose painting

\section{Introduction}

In radiation therapy $(\mathrm{RT})$, modern treatment techniques distinguish themselves by an exceptional flexibility in dose delivery. With techniques such as intensity-modulated RT (IMRT) and volumetric-modulated arc therapy (VMAT), complex dose distributions can be realized, so that a tumor can be exposed to a lethal radiation dose, while nearby healthy tissue can be optimally spared. With brachytherapy,

* Corresponding author. Tel.: +31205122350.

E-mail address: u.vd.heide@nki.nl (U.A. van der Heide). radioactive sources are positioned inside (or in close proximity to) the tumor. This again results in a high tumor dose, with minimal exposure of surrounding healthy tissue. A reliable delivery of these complex treatments is ensured with imaging of the patient in the treatment room. For this purpose, cone-beam computed tomography (CT) scanners are attached to the linear accelerator making image-guided radiotherapy (IGRT) feasible [1,2]. Strategies for precise irradiation of moving tumors (gating/tracking) have been developed. As part of the brachytherapy procedure, patients increasingly receive some form of three-dimensional (3D) imaging [CT or magnetic resonance imaging (MRI)] to verify the application $[3,4]$. With these technological 
innovations in RT, an improvement in tumor control is no longer invariably associated with an increase in radiationinduced toxicity $[2,5]$.

RT has the capacity for differential treatment, in which a high dose can be delivered to the visible tumor, whereas tissue holding microscopic disease is irradiated with a lower dose. In this way, tumor cells are eradicated while the underlying healthy tissue is allowed to recover. This capacity sets it apart from all-or-nothing therapies, such as surgery. Taking this concept a step further, Ling et al. [6] proposed to use biological imaging to achieve "biological conformality" by escalating the dose to parts of the tumor that are particularly aggressive or radiation resistant, while reducing the dose to less aggressive parts. This new approach is called dose painting $[7,8]$. Several theoretical studies showed that treatment plans indeed can be modulated to match the biological properties reflected by functional imaging modalities [8-10]. Aerts et al. [11,12] confirmed that certain areas within the gross tumor volume are more therapy resistant. Malinen et al. [13] investigated the potential of dose painting based on dynamic contrast-enhanced MRI in natural nasopharynx tumors in dogs.

For dose painting to be effective, high-quality imaging of the tumor and surrounding tissue is required. In this review, we will describe developments in MRI-guided dose painting and identify the issues that must be addressed when applying MRI in the context of a radiotherapy treatment.

\section{Imaging for radiotherapy}

Anatomical and functional MRIs are commonly used in a diagnostic setting. For many tumor sites, the sensitivity and specificity of combinations of techniques for tumor detection and staging have been established.

The purpose of an MRI exam for radiotherapy treatment planning is, however, distinctly different from most diagnostic exams. At the time a patient arrives at a radiation oncology department, the diagnosis of cancer is established and staging of the disease is already finalized. For RT planning, the imaging information is now used to create a precise delineation of the target volume. Treatment portals are calculated based on these delineations, to provide an optimal dose distribution (Fig. 1). In clinical trials, testing the benefit of dose painting, the imaging of tumor characteristics is used to make decisions on dose levels.

Anatomical imaging, for example, with $T_{2}$-weighted MRI, can provide information on the spread of tumor tissue. However, to assess the microenvironment within a solid tumor, functional techniques seem to be more promising. Up to now, most experience has been obtained with ${ }^{18} \mathrm{~F}$ fluorodeoxyglucose positron emission tomography (FDGPET) [14-17]. In head and neck cancer, phase I trials were carried out to investigate the toxicity of dose escalation in the FDG-PET-positive part of the tumor [18,19]. For non-small

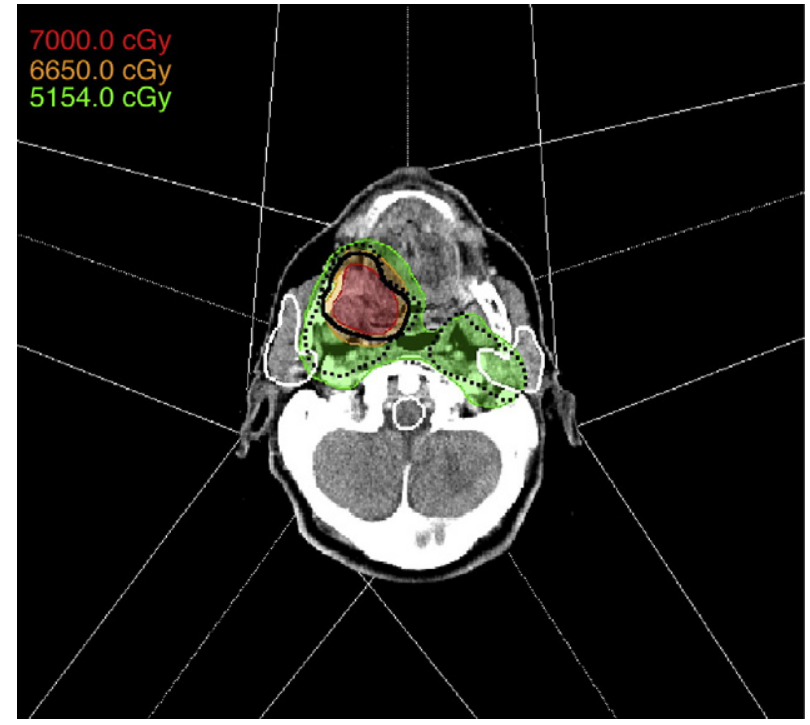

Fig. 1. Example of a radiation therapy treatment geometry with beams irradiating the tumor from multiple directions (solid black line: primary tumor; dashed black line: clinical target volume, with microscopic disease; white line: parotid glands and spinal cord).

cell lung cancer, a trial is currently ongoing that also escalates dose to the part of the tumor with high standardized uptake values, which has been shown in several studies to be more radiation resistant $[11,12,15,20]$.

FDG-PET reflects the glucose uptake of tissue, related to the metabolic activity of tumor tissue and the level of hypoxia response. It is, however, important to recognize that other properties are potentially relevant to guide radiotherapy treatments: density of tumor cells, acidosis, proliferation, density of tumor stem cells and oxygenation of the tissue are factors that influence the radiation sensitivity of a tumor. With a combination of functional MRI techniques, such properties can be imaged: diffusion-weighted MRI (DWI) reflects the microscopic mobility of water in the cellular environment. As a result, it is sensitive to the "microanatomy" of the tissue, such as cellular density and organization of the cellular and extracellular space. In tumors, typically a restricted diffusion is found, as compared to normal tissue. While this generally is attributed to an increased cellular density, other changes in microanatomy also may play a role [21]. In dynamic contrast-enhanced (DCE) MRI, the temporal changes in signal upon administration of contrast agent reflect the blood flow in tissue as well as the extravasation of contrast agent from microvessels into the interstitial space. Tumor growth relies on the formation of new blood vessels to provide oxygenation of the tissue. However, this new vascular structure tends to be highly disorganized and shows shunt perfusion. As a result, the contrast enhancement patterns in tumor can differ distinctly from normal tissue [22]. Both DWI and DCE-MRI are often used as an early marker of tumor response during anticancer therapy [23]. 


\subsection{Use of multiparametric imaging}

The use of more than one (functional) imaging technique to visualize the tumor and surrounding tissue is common practice in diagnostic examinations, where the purpose is the characterization and staging of the disease. For many types of cancer, studies showed that adding more (functional) imaging modalities improves the sensitivity and specificity of an exam. For example, Turkbey et al. [24] showed in prostate cancer that $T_{2}$-weighted MRI, DCEMRI and MR spectroscopic imaging (MRSI) all three provided an independent (additive) predictive value for tumor detection. Adding all modalities improved the accuracy of the examination.

For radiotherapy target delineation, the addition of multiple techniques is not as straightforward. Even when all modalities point at the presence of a tumor in a particular location, the precise boundary of the tumor is not as easy to assess. Target delineation is particularly difficult when different techniques appear to provide conflicting information [25]. Simple thresholding of maps of apparent diffusion coefficients (ADCs) or tracer kinetic parameters such as $K^{\text {trans }}$ may not be appropriate [26]. To increase the robustness of the interpretation of multiparametric MRI data, models have been proposed that use support-vector machines [27] or logistic regression [28-30].

These studies use multiparametric MRI data to improve tumor detection, possibly on the level of individual voxels. For dose painting, it would be relevant to identify if particular (combinations of) imaging modalities correlate with tumor aggressiveness and sensitivity to radiation. One way to do so is to perform "pattern of relapse studies" $[11,12,31]$.

To take benefit from these imaging techniques within a high-precision RT treatment, new questions must be addressed. Scanning in treatment position requires alternative solutions to the standard patient setup as well as the choice of receive coils compared to a diagnostic department. The geometrical accuracy of MR images is critical for high-precision radiotherapy. In particular, when multiparametric functional data are used for dose painting, quantification of functional parameters at a high spatial resolution becomes important.

\section{Technical challenges for the use of MRI for RT dose painting}

\subsection{Radiotherapy-compatible patient position}

External-beam RT is mostly delivered in a series of daily irradiation sessions that can last up to 2 months. To achieve a precise dose delivery, it is therefore essential that the patient can be positioned reproducibly from day to day. Obviously, images that form the basis for a treatment plan must be made in the same position. The CT scan used for setting up treatment portals and for dose calculations (planning CT) is usually made in an RT department, where identical setup procedures are applied. Laser systems in the CT room define a frame of reference that is copied at the linear accelerator in the treatment room during treatment. Wide-bore CT scanners have removed most of the limitations for scanning the patient in the treatment position. This way of patient positioning differs from the typical practice at an MRI scanner. Due to the duration of the MRI exam, patient comfort is more of a concern. As most MRI exams are not repeated, the reproducibility of the position is not an issue. Usually, a solution can be found that is both reproducible and comfortable for the patient.

For irradiation of tumors in the pelvis, it is standard practice to position patients on a flat table top. In MRI, body phased-array coils are often placed around the patient. To create a flat surface similar to a flat table top, a thin, but firm insert can be positioned on top of the coils.

Patients treated for head and neck cancer lie on a pad and are fixated in a personalized mask to guarantee a reproducible orientation and flexing of the neck. The fixation mask does not fit in most head coils used for head and neck MRI. Here creative solutions need to be developed. Verduijn et al. [32] investigated how to obtain the diagnostic quality MRI scans of head and neck tumors while scanning the patient in a mask. The use of a set of flexible surface coils, attached to the mask, provided a good alternative. In our clinic, we use two sets of flexible surface coils, to improve coverage and image quality (Fig. 2). Nevertheless, multichannel head coils are advantageous for imaging, and solutions to fit RT masks in such systems are needed.

For breast cancer, the differences in positioning practice are even more striking: in MRI, patients are usually scanned in prone position, in a dedicated breast coil, as compared to supine, lying on a wedge-shaped support in radiotherapy (Fig. 3). Siegler et al. [33] showed that supine breast MRI resulted in comparable image quality as regular diagnostic MRI. Positioning on a radiotherapy wedge support may be

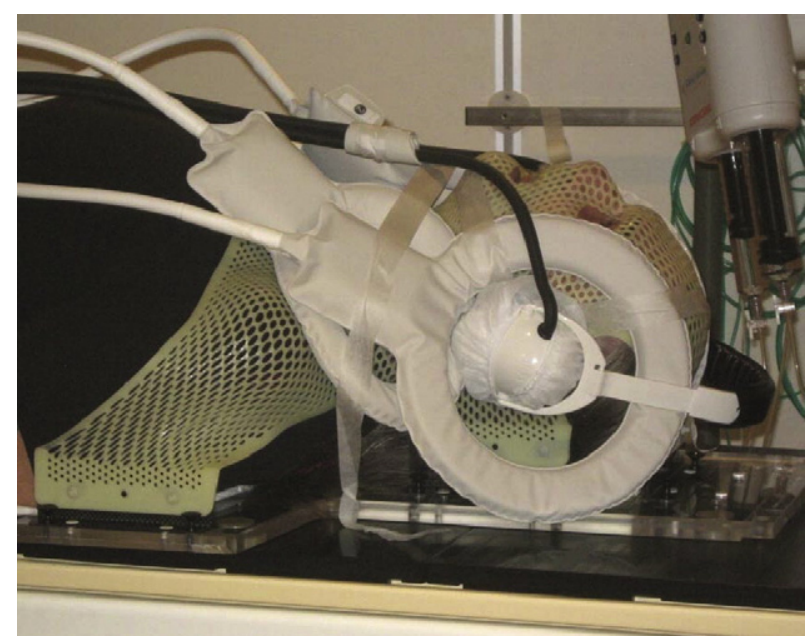

Fig. 2. Head coil configuration of two sets of flexible surface coils, attached to a radiotherapy fixation mask. 


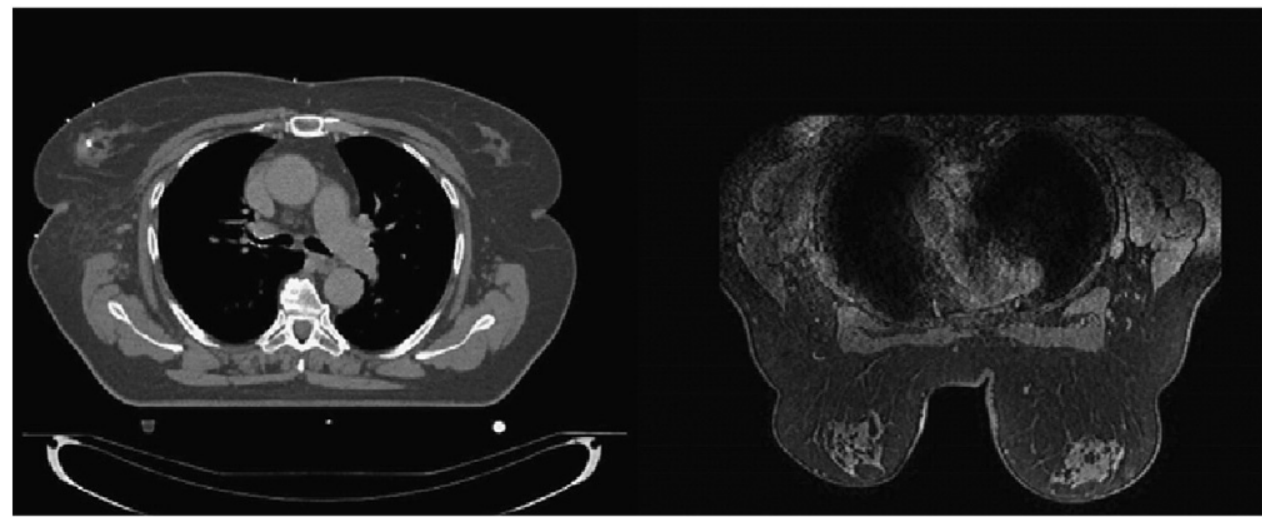

Fig. 3. Left: planning CT scan for radiotherapy, with patient supine, on a wedge support system. Right: diagnostic $T_{2}$-weighted MRI, with patient prone, using breast coil.

feasible particularly in wide-bore MRI scanners that are now commercially available.

\subsection{Spatial resolution and geometrical accuracy}

For a limited number of cancers, guidelines have been published for tumor delineation based on MRI. In most cases, $T_{2}$-weighted spin echo sequences are used for this purpose [34-36]. A disadvantage of these sequences is that slices tend to be quite thick ( $3 \mathrm{~mm}$ or more). Inevitably, delineations of tumors are inprecise in the slice direction. As the precision of radiotherapy delivery has improved to the order of a millimeter, the thickness of the imaging slices becomes a limiting factor. For this reason, 3D sequences with a high resolution in all directions are of interest [37].

Since the geometry of the treatment portals is based on the delineations of the tumor on MRI, the geometrical accuracy of these images is a matter of concern. Errors in tumor delineation may result in undertreatment of the tumor or in unnecessary exposure of healthy tissue.

Geometrical distortions are caused by nonlinearities in the gradient coils as well as by inhomogeneities in the static magnetic $B_{0}$ field [38]. The latter are, to some extent, an intrinsic property of the scanner. However, air tissue transitions, in particular in cavities in the body, can cause substantial $B_{0}$ field distortions as well. Scanner-related distortions can be characterized with phantoms with a grid of fluid-filled rods. With combinations of images with opposite gradient directions, both scanner-related $B_{0}$ and gradient errors can be measured [39-41]. In principle, these scanner-specific distortions can be corrected via lookup tables. [40]. For patient-induced $B_{0}$ field distortions, depending on the specific anatomy, this is not a viable option. However, the distortions can be visualized by comparing images with opposite readout gradient directions. Several correction techniques have been described, involving the mapping of image features from one image to the other. However, the correction of realistic images, with complex contrast patterns and chemical-shift artifacts, can be difficult. Reinsberg et al. [42] showed that the best results for correction of images of humans were achieved with a mutual information-based approach for mapping of the two images acquired with opposite readout gradients.

For stereotactic radiosurgery of brain tumors, the geometrical accuracy of the entire treatment is pushed to its limits. Patients are often scanned in a stereotactic frame for fixation. Zhang et al. [43] developed a geometrically accurate imaging protocol at a 3.0-T scanner for stereotactic radiosurgery. In a comparison between 1.5- and 3.0-T magnets, the same group showed that for two sets of spoiled gradient echo and fast-relaxation fast-spin echo sequences, the mean discrepancy in tumor surface was significantly less than $1 \mathrm{~mm}$, with no differences in delineated volume $[43,44]$.

In brachytherapy, radioactive sources are brought in close proximity of the tumor tissue via catheters and applicators. As the dose from these sources falls quadratically with the distance, the geometrical accuracy of MR images used for treatment planning is extremely important. Susceptibility artifacts caused by an applicator must be minimized. For this reason, standard metal applicators are replaced by plastic applicators. However, titanium needles are commonly used for interstitial treatments. Haack et al. [45] investigated the accuracy of localizing the source channels inside applicators and needles for brachytherapy of cervical cancer. Using $T_{1^{-}}$ and $T_{2}$-weighted turbo spin echo sequences, differences with CT were less than half the slice thickness and an interobserver variation smaller than $1 \mathrm{~mm}$ was found.

Geometrical accuracy is also relevant when functional MRI techniques are used to define the boundaries of a tumor volume. DWI particularly suffers from geometrical deformations that are associated with echo-planar imaging (EPI) sequences. Although it is recommended to maximize bandwidth, for example, by using parallel imaging [23], distortions can be large in close proximity to air-tissue interfaces. Retrospective correction of EPI images can be applied, using a $B_{0}$ field map [46], but the effectiveness of such a procedure close to air cavities is uncertain. 


\subsection{Quantification of functional MRI}

The accuracy of target definition is also influenced by the quantification of functional parameters. In Fig. 4, an example of a $K^{\text {trans }}$ image obtained from DCE-MRI is shown. By simply changing the threshold, the perception of the tumor size can change dramatically. While the localization of the tumor is relatively insensitive to the threshold, uncertainties in the interpretation of $K^{\text {trans }}$ values may result in quite different target volumes for irradiation. While in PET, abundant literature exists to deal with quantification and determination of thresholds for tumor delineation [47-50], for functional MRI techniques such, studies are currently lacking.

The spatial resolution of functional imaging modalities is most relevant in the context of dose painting. To image the heterogeneity within the tumor, a high spatial resolution is called for. However, as in each voxel, the dose prescription essentially is derived from the value of (combinations of) functional parameters; the question is at what spatial resolution consistent functional parameter values can still be obtained.

Only few studies investigated the reproducibility of functional techniques, and even fewer addressed the relation between image noise, voxel size and repeatability. Lambregts et al. [51] have shown that the size and positioning of the region of interest (ROI) for ADC calculations in patients with rectal cancer have a considerable influence on tumor $\mathrm{ADC}$ values and interobserver variability.

The reproducibility of DWI of the prostate was studied by Gibbs et al. [52] and varied between $10 \%$ and 35\%, depending on experimental conditions. Increasing the number of signal averages improved the repeatability, but varying the size of the ROI from 0.3 to $1.7 \mathrm{cc}$ seemed to have little impact. The impact of geometrical distortions on voxelwise repeatability of DWI data is as yet unclear and requires further investigation.

For DCE-MRI, quantification is generally considered quite complex. To improve the consistency of reporting of DCE-MRI data, Tofts et al. [53] proposed a standardization of the tracer kinetic model and nomenclature. Nevertheless, large differences have been reported in the value of the transfer constant, $K^{\text {trans }}$, in healthy $\left(0.06-0.60 \mathrm{~min}^{-1}\right)$ and cancerous $\left(0.18-1.26 \mathrm{~min}^{-1}\right)$ prostate tissue [54-60]. This variation is not caused by a day-to-day variability in the patient, as the within subject standard deviation (wSD) of $K^{\text {trans }}$ from DCE-MRI is reported to be small (wSD $=0.10$ $\mathrm{min}^{-1}$ for MRI, 0.047 for voxels of $0.15 \mathrm{cc}$ on DCE-CT) [61]. Thus, further standardization in methodology may result in a more robust quantification of DCE-MRI, making it even more attractive for use in dose painting,

\section{Future prospects}

The use of MRI has just started to spread into the daily practice in radiation oncology. Several innovations in this field have a high potential to result in further improvements in the treatment.

\subsection{Improved precision in $R T$}

The quantitative use of images to decide both where and how to deliver RT in an individual case is also called theragnostic imaging. IMRT is now a widely used treatment modality for patients with head and neck cancer. The dose distributions from IMRT are static and, thus, are unable to account for variations and/or uncertainties in the relationship between the patient (region being treated) and the beam. Organ motion comprises one such source of this uncertainty, introduced by physiological variation in the position, size and shape of organs during treatment. In the head and neck area, the predominant source of this variation arises from deglutition (swallowing). As an example, studies investigated whether cinematographic MRI (cine MRI) could be used to determine asymmetric (nonuniform) internal margin components of tumor planning target volumes based on the actual deglutition-induced tumor displacement. Another example is the hearing preservation after treatment of vestibular schwannoma; critical hearing preservation variables include (1) strict attention to prescription dose $3 \mathrm{D}$

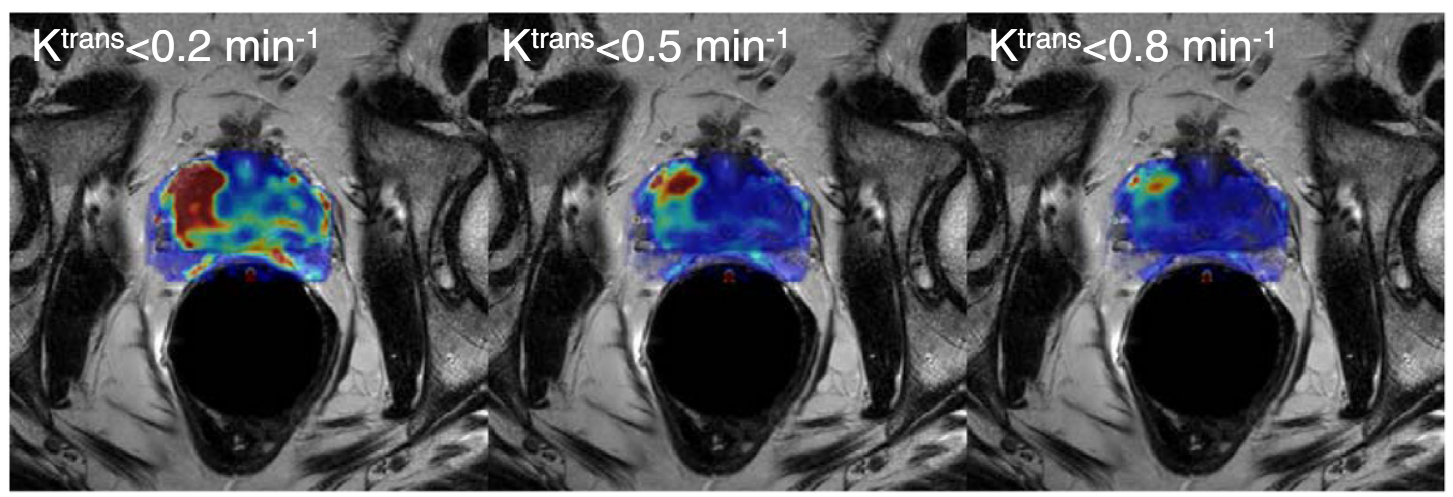

Fig. 4. $T_{2}$-weighted MRI of a patient with prostate cancer, with color overlay of $K^{\text {trans }}$ with three different thresholds, changing the apparent size of the tumor in the right peripheral zone (left in the images). 
conformality so that the ventral cochlear nucleus receives less than or equal to $9 \mathrm{~Gy}$ and (2) careful delineation of the 3D tumor boundary to exclude the cochlear nerve when visualized with contrast-enhanced $T_{2}$-weighted MR volumetric imaging techniques and exclusion of the dura mater of the anterior border of the internal auditory canal [62].

Multiple functional MRI techniques for detection of prostate cancer are now used to define the tumor inside the prostate as a target for further dose escalation with IMRT or VMAT $[63,64]$. This approach is motivated by evidence that local recurrences are mostly found at the location of the primary tumor $[65,66]$. At the moment, this approach is tested in a phase III multicenter trial [67].

The incorporation of MRSI data in the definition of radiotherapy target volumes for selective boosting may be a promising avenue leading to increased local control of glioblastomas [68].

A recent paper by Thorwarth et al. [69] showed that differences in target volumes delineated on the basis of separate MR and PET/CT and simultaneous PET/MR may be observed, which can have significant consequences for an effectively applied radiotherapy treatment plan.

Data are emerging, reporting that with DWI, rises in ADC during or after preoperative chemoradiotherapy may be useful for the prediction and evaluation of response in patients with locally advanced rectal cancer, although at the time of writing, the evidence is not strong and from small single-center studies [70-72]. A few studies concluded that the combination of the different time points and the different imaging modalities increased the specificity of the response assessment both during and after chemoradiotherapy [73].

\subsection{MRI-guided radiotherapy}

The adoption of IMRT to treat cervical malignancies has been limited, in part, by complex organ and tumor motion during treatment. Several studies explore the benefits of a highly adaptive, small-margin treatment scenario to accommodate this motion [74]. In radiotherapy, the healthy tissue involvement still poses serious dose limitations. This results in suboptimal tumor dose and complications. Daily IGRT is the key development in radiation oncology to solve this problem. MRI yields superb soft tissue visualization and provides several imaging modalities for identification of movements, function and physiology. Integrating MRI functionality with an accelerator, the so-called MR linac, can make these capacities available for high-precision $[75,76]$, real-time IGRT. The Holy Grail would be to combine MR with the most accurate radiotherapy technique such as proton therapy [77].

The clinical feasibility of magnetic resonance imageguided adaptive brachytherapy (IGABT) for patients with locally advanced vaginal and cervix cancer has been reported with excellent treatment outcomes [78]. Also, dose-response relationships for late side effects of the rectum and bladder in cervix cancer patients after magnetic resonance IGABT have been established. There has also been an interesting development with MR thermometry to monitor hyperthermia used in combination with radiotherapy. Ultimately, these technological improvements should lead to an improved clinical outcome; as mentioned above, several dose painting trials are currently attempting to demonstrate this.

\section{Conclusion}

In recent years, a considerable research effort has been dedicated to the integration of MRI into the external radiotherapy workflow motivated by the superior soft tissue contrast as compared to CT.

In this review, we have addressed these issues and described clinical developments in MRI-guided dose painting such as improved precision in delivery in RT, use of combinations of functional MR (and PET), MRI-guided radiotherapy (MR-linacs, MR-guided brachytherapy, MR for proton therapy) and dose painting trials.

\section{Acknowledgments}

We acknowledge financial support from the EU IMI program (QuIC-ConCePT), the CTMM framework (AIRFORCE project), EU 7th framework program (Metoxia program) and NIH-QIN (Radiomics of NSCLC U01 CA143062).

\section{References}

[1] Mageras GS, Mechalakos J. Planning in the IGRT context: closing the loop. Semin Radiat Oncol 2007;17:268-77.

[2] Bujold A, Craig T, Jaffray D, Dawson L. Image-guided radiotherapy: has it influenced patient outcomes? Semin Radiat Oncol 2012;22: 50-61.

[3] Haie-Meder C, Siebert FA, Pötter R. Image guided, adaptive, accelerated, high dose brachytherapy as model for advanced small volume radiotherapy. Radiother Oncol 2011;100:333-43.

[4] Tanderup K, Georg D, Pötter R, Kirisits C, Grau C, Lindegaard JC. Adaptive management of cervical cancer radiotherapy. Semin Radiat Oncol 2010;20:121-9.

[5] De Neve W, De Gersem W, Madani I. Rational use of intensitymodulated radiation therapy: the importance of clinical outcome. Semin Radiat Oncol 2012;22:40-9.

[6] Ling CC, Humm J, Larson S, Amols H, Fuks Z, Leibel S, et al. Towards multidimensional radiotherapy (MD-CRT): biological imaging and biological conformality. Int J Radiat Oncol Biol Phys 2000;47: 551-60.

[7] Bentzen SM. Theragnostic imaging for radiation oncology: dosepainting by numbers. Lancet Oncol 2005;6:112-7.

[8] Thorwarth D, Eschmann SM, Paulsen F, Alber M. Hypoxia dose painting by numbers: a planning study. Int J Radiat Oncol Biol Phys 2007;68:291-300.

[9] Bowen SR, Flynn RT, Bentzen SM, Jeraj R. On the sensitivity of IMRT dose optimization to the mathematical form of a biological imaging-based prescription function. Phys Med Biol 2009;54: 1483-501.

[10] Petit SF, Dekker ALAJ, Seigneuric R, Murrer L, van Riel NAW, Nordsmark M, et al. Intra-voxel heterogeneity influences the dose 
prescription for dose-painting with radiotherapy: a modelling study. Phys Med Biol 2009;54:2179-96.

[11] Aerts HJWL, van Baardwijk AAW, Petit SF, Offermann C, van Loon $\mathrm{J}$, Houben R, et al. Identification of residual metabolic-active areas within individual NSCLC tumours using a pre-radiotherapy (18) fluorodeoxyglucose-PET-CT scan. Radiother Oncol 2009;91:386-92.

[12] Aerts HJWL, Bussink J, Oyen WJG, van Elmpt W, Folgering AM, Emans D, et al. Identification of residual metabolic-active areas within NSCLC tumours using a pre-radiotherapy FDG-PET-CT scan: a prospective validation. Lung Cancer 2012;75:73-6.

[13] Malinen E, Søvik A, Hristov D, Bruland ØS, Olsen DR. Adapting radiotherapy to hypoxic tumours. Phys Med Biol 2006;51:4903-21.

[14] van Loon J, Janssen MHM, Ollers M, Aerts HJWL, Dubois L, Hochstenbag M, et al. PET imaging of hypoxia using [18F]HX4: a phase I trial. Eur J Nucl Med Mol Imaging 2010;37:1663-8.

[15] Lambin P, Petit SF, Aerts HJWL, van Elmpt WJC, Oberije CJG, Starmans MHW, et al. Breur Lecture 2009. From population to voxelbased radiotherapy: exploiting intra-tumour and intra-organ heterogeneity for advanced treatment of non-small cell lung cancer. Radiother Oncol 2010;96:145-52.

[16] Dubois LJ, Lieuwes NG, Janssen MHM, Peeters WJM, Windhorst AD, Walsh JC, et al. Preclinical evaluation and validation of [18F]HX4, a promising hypoxia marker for PET imaging. Proc Natl Acad Sci U S A 2011;108:14620-5.

[17] van den Bogaard J, Janssen MHM, Janssens G, Buijsen J, Reniers B, Lambin $\mathrm{P}$, et al. Residual metabolic tumor activity after chemoradiotherapy is mainly located in initially high FDG uptake areas in rectal cancer. Radiother Oncol 2011;99:137-41.

[18] Madani I, Duthoy W, Derie C, De Gersem W, Boterberg T, Saerens M, et al. Positron emission tomography-guided, focal-dose escalation using intensity-modulated radiotherapy for head and neck cancer. Int J Radiat Oncol Biol Phys 2007;68:126-35.

[19] Duprez F, De Neve W, De Gersem W, Coghe M, Madani I. Adaptive dose painting by numbers for head-and-neck cancer. Int J Radiat Oncol Biol Phys 2011;80:1045-55.

[20] PET Boost trial. Dose escalation by boosting radiation dose within the primary tumor on the basis of a pre-treatment FDG-PET-CT scan in stage IB, II and III NSCLC: a randomized Phase II trial. www. clinicaltrials.gov. NCT01024829.

[21] Padhani AR, Liu G, Koh DM, Chenevert TL, Thoeny HC, Takahara T, et al. Diffusion-weighted magnetic resonance imaging as a cancer biomarker: consensus and recommendations. Neoplasia 2009;11: 102-25.

[22] Brix G, Griebel J, Kiessling F, Wenz F. Tracer kinetic modelling of tumour angiogenesis based on dynamic contrast-enhanced $\mathrm{CT}$ and MRI measurements. Eur J Nucl Med Mol Imaging 2010;37:S30-51.

[23] Padhani AR, Khan AA. Diffusion-weighted (DW) and dynamic contrast-enhanced (DCE) magnetic resonance imaging (MRI) for monitoring anticancer therapy. Target Oncol 2010;5:39-52.

[24] Turkbey B, Pinto PA, Mani H, Bernardo M, Pang Y, McKinney YL, et al. Prostate cancer: value of multiparametric MR imaging at $3 \mathrm{~T}$ for detection - histopathologic correlation. Radiology 2010;255:89-99.

[25] Buijsen J, van den Bogaard J, Janssen MHM, Bakers FCH, Engelsman $\mathrm{S}$, Öllers $\mathrm{M}$, et al. FDG-PET provides the best correlation with the tumor specimen compared to MRI and CT in rectal cancer. Radiother Oncol 2011;98:270-6.

[26] Groenendaal G, van den Berg CAT, Korporaal JG, Philippens MEP, Luijten PR, van Vulpen M, et al. Simultaneous MRI diffusion and perfusion imaging for tumor delineation in prostate cancer patients. Radiother Oncol 2010;95:185-90.

[27] Vos PC, Hambrock T, Hulsbergen-van de Kaa CA, Fütterer JJ, Barentsz JO, Huisman HJ. Computerized analysis of prostate lesions in the peripheral zone using dynamic contrast enhanced MRI. Med Phys 2008;35:888-99.

[28] Langer DL, van der Kwast TH, Evans AJ, Trachtenberg J, Wilson BC, Haider MA. Prostate cancer detection with multi-parametric MRI: logistic regression analysis of quantitative $T_{2}$, diffusion-weighted imaging, and dynamic contrast-enhanced MRI. J Magn Reson Imaging 2009;30:327-34.

[29] Ozer S, Langer DL, Liu X, Haider MA, van der Kwast TH, Evans AJ, et al. Supervised and unsupervised methods for prostate cancer segmentation with multispectral MRI. Med Phys 2010;37:1873-83.

[30] Groenendaal G, Borren A, Moman MR, Monninkhof E, van Diest PJ, Philippens ME, et al. Pathologic validation of a model based on diffusion-weighted imaging and dynamic contrast-enhanced magnetic resonance imaging for tumor delineation in the prostate peripheral zone. Int J Radiat Oncol Biol Phys 2012;82:e537-44.

[31] van Vulpen M, van den Berg CAT, Moman MR, van der Heide UA. Difficulties and potential of correlating local recurrences in prostate cancer with the delivered local dose. Radiother Oncol 2009;93:180-4.

[32] Verduijn GM, Bartels LW, Raaijmakers CP, Terhaard CH, Pameijer FA, van den Berg CA. Magnetic resonance imaging protocol optimization for delineation of gross tumor volume in hypopharyngeal and laryngeal tumors. Int J Radiat Oncol Biol Phys 2009;74:630-6.

[33] Siegler P, Holloway CMB, Causer P, Thevathasan G, Plewes DB. Supine breast MRI. J Magn Reson Imaging 2011;34:1212-7.

[34] Haie-Meder C, Pötter R, Van Limbergen E, Briot E, De Brabandere M, Dimopoulos J, et al. Recommendations from gynaecological (GYN) GEC-ESTRO working group (I): concepts and terms in 3D image based 3D treatment planning in cervix cancer brachytherapy with emphasis on MRI assessment of GTV and CTV. Radiother Oncol 2005;74:235-45.

[35] Villeirs GM, Verstraete KL, De Neve WJ, De Meerleer GO. Magnetic resonance imaging anatomy of the prostate and periprostatic area: a guide for radiotherapists. Radiother Oncol 2005;76:99-106.

[36] McLaughlin PW, Troyer S, Berri S, Narayana V, Meirowitz A, Roberson PL, et al. Functional anatomy of the prostate: implications for treatment planning. Int J Radiat Oncol Biol Phys 2005;63:479-91.

[37] Khoo VS, Padhani AR, Tanner SF, Finnigan DJ, Leach MO, Dearnaley DP. Comparison of MRI with CT for the radiotherapy planning of prostate cancer: a feasibility study. Br J Radiol 1999;72: $590-7$.

[38] Sumanaweera TS, Glover GH, Binford TO, Adler JR. MR susceptibility misregistration correction. IEEE Trans Med Imaging 1993;12: 251-9.

[39] Chang H, Fitzpatrick JM. A technique for accurate magnetic resonance imaging in the presence of field inhomogeneities. IEEE Trans Med Imaging 1992;11:319-29.

[40] Bakker CJG, Moerland MA, Bhagwandien R, Beersma R. Analysis of machine-dependent and object-induced geometric distortions in 2DFT MR imaging. Magn Reson Imaging 1992;10:597-608.

[41] Moerland MA, Beersma R, Bhagwandien R, Wijrdeman HK, Bakker CJG. Analysis and correction of geometric distortions in $1.5 \mathrm{~T}$ magnetic resonance images for use in radiotherapy treatment planning. Phys Med Biol 1995;40:1651-64

[42] Reinsberg SA, Doran SJ. A complete distortion correction for MR images: II. Rectification of static-field inhomogeneities by similaritybased profile mapping. Phys Med Biol 2005;50:2651-61.

[43] Zhang B, MacFadden D, Damyanovich AZ, Rieker M, Stainsby J, Bernstein M, et al. Development of a geometrically accurate imaging protocol at 3 Tesla MRI for stereotactic radiosurgery treatment planning. Phys Med Biol 2010;55:6601-15.

[44] MacFadden D, Zhang B, Brock KK, Hodaie M, Laperriere N, Schwartz M, et al. Clinical evaluation of stereotactic target localization using 3-Tesla MRI for radiosurgery planning. Int J Radiat Oncol Biol Phys 2010;76:1472-9.

[45] Haack S, Nielsen SK, Lindegaard JC, Gelineck J, Tanderup K. Applicator reconstruction in MRI 3D image-based dose planning of brachytherapy for cervical cancer. Radiother Oncol 2009;91:187-93.

[46] Jezzard P, Balaban RS. Correction for geometric distortion in echo planar images from $B_{0}$ field variations. Magn Reson Med 1995;34: $65-73$.

[47] Nestle U, Kremp S, Schaefer Schuler A, Sebastian Welsch C, Hellwig $\mathrm{D}$, Rübe $\mathrm{C}$, et al. Comparison of different methods for delineation of 
18F-FDG PET-positive tissue for target volume definition in radiotherapy of patients with non-small cell lung cancer. J Nucl Med 2005;46:1342-8.

[48] Geets X, Lee JA, Bol A, Lonneux M, Grégoire V. A gradient-based method for segmenting FDG-PET images: methodology and validation. Eur J Nucl Med Mol Imaging 2007;34:1427-38.

[49] Schaefer A, Kremp S, Hellwig D, Rübe C, Kirsch CM, Nestle U. A contrast-oriented algorithm for FDG-PET-based delineation of tumour volumes for the radiotherapy of lung cancer: derivation from phantom measurements and validation in patient data. Eur J Nucl Med Mol Imaging 2008;35:1989-99.

[50] Lee JA. Segmentation of positron emission tomography images: some recommendations for target delineation in radiation oncology. Radiother Oncol 2010;96:302-7.

[51] Lambregts DM, Beets GL, Maas M, Curvo-Semedo L, Kessels AG, Thywissen T, et al. Tumour ADC measurements in rectal cancer: effect of ROI methods on ADC values and interobserver variability. Eur Radiol 2011;12:2567-74.

[52] Gibbs P, Pickles MD, Turnbull LW. Repeatability of echo-planarbased diffusion measurements of the human prostate at $3 \mathrm{~T}$. Magn Reson Imaging 2007;25:1423-9.

[53] Tofts PS, Brix G, Buckley DL, Evelhoch JL, Henderson E, Knopp $\mathrm{MV}$, et al. Estimating kinetic parameters from dynamic contrastenhanced $T_{1}$-weighted MRI of a diffusable tracer: standardized quantities and symbols. J Magn Reson Imaging 1999;10:223-32.

[54] van Dorsten FA, van der Graaf M, Engelbrecht MRW, van Leenders GJLH, Verhofstad A, Rijpkema M, et al. Combined quantitative dynamic contrast-enhanced MR imaging an $1 \mathrm{H}$ MR spectroscopic imaging of human prostate cancer. J Magn Reson Imaging 2004;20:279-87.

[55] Buckley DL, Roberts C, Parker GJM, Logue JP, Hutchinson CE. Prostate cancer: evaluation of vascular characteristics with dynamic contrast-enhanced $T_{1}$-weighted MR imaging - initial experience. Radiology 2004;233:709-15.

[56] Kozlowski P, Chang SD, Jones EC, Berean KW, Chen H, Goldenberg SL. Combined diffusion-weighted and dynamic contrast-enhanced MRI for prostate cancer diagnosis - correlation with biopsy and histopathology. J Magn Reson Imaging 2006;24:108-13.

[57] Ocak I, Bernardo M, Metzger G, Barrett T, Pinto P, Albert PS, et al. Dynamic contrast-enhanced MRI of prostate cancer at $3 \mathrm{~T}$ : a study of pharmacokinetic parameters. Am J Roentgenol 2007;189:849.

[58] Alonzi R, Taylor NJ, Stirling JJ, d'Arcy JA, Collins DJ, Saunders MI, et al. Reproducibility and correlation between quantitative and semiquantitative dynamic and intrinsic susceptibility-weighted MRI parameters in the benign and malignant human prostate. J Magn Reson Imaging 2010;32:155-64.

[59] Kozlowski P, Chang SD, Meng R, Mädler B, Bell R, Jones EC, et al. Combined prostate diffusion tensor imaging and dynamic contrast enhanced MRI at 3T - quantitative correlation with biopsy. Magn Reson Imaging 2010;28:621-8.

[60] Langer DL, van der Kwast TH, Evans AJ, Plotkin A, Trachtenberg J, Wilson BC, et al. Prostate tissue composition and MR measurements: investigating the relationships between $\mathrm{ADC}, T_{2}, K(\operatorname{trans}), v(e)$, and corresponding histologic features. Radiology 2010;255:485-94.

[61] Korporaal JG, van den Berg CAT, Jeukens CRLPN, Groenendaal G, Moman MR, Luijten P, et al. Dynamic contrast-enhanced CT for prostate cancer: relationship between image noise, voxel size, and repeatability. Radiology 2010;256:976-84.

[62] Linskey ME. Hearing preservation in vestibular schwannoma stereotactic radiosurgery: what really matters? J Neurosurg 2008;109(Suppl.):129-36.

[63] Singh AK, Guion P, Sears-Crouse N, Ullman K, Smith S, Albert PS, et al. Simultaneous integrated boost of biopsy proven, MRI defined dominant intra-prostatic lesions to 95 Gray with IMRT: early results of a phase I NCI study. Radiat Oncol 2007;2:36.
[64] Fonteyne V, Villeirs G, Speleers B, De Neve W, De Wagter C, Lumen $\mathrm{N}$, et al. Intensity-modulated radiotherapy as primary therapy for prostate cancer: report on acute toxicity after dose escalation with simultaneous integrated boost to intraprostatic lesion. Int J Radiat Oncol Biol Phys 2008;72:799-807.

[65] Cellini N, Morganti AG, Mattiucci GC, Valentini V, Leone M, Luzi S, et al. Analysis of intraprostatic failures in patients treated with hormonal therapy and radiotherapy: implications for conformal therapy planning. Int J Radiat Oncol Biol Phys 2002;53: 595-9.

[66] Pucar D, Hricak H, Shukla-Dave A, Kuroiwa K, Drobnjak M, Eastham $\mathrm{J}$, et al. Clinically significant prostate cancer local recurrence after radiation therapy occurs at the site of primary tumor: magnetic resonance imaging and step-section pathology evidence. Int J Radiat Oncol Biol Phys 2007;69:62-9.

[67] Lips IM, van der Heide UA, Haustermans K, van Lin ENJT, Pos F, Franken SPG, et al. Single blind randomized phase III trial to investigate the benefit of a focal lesion ablative microboost in prostate cancer (FLAME-trial): study protocol for a randomized controlled trial. Trials 2011;12:255.

[68] Laprie A, Catalaa I, Cassol E, McKnight TR, Berchery D, Marre D, et al. Proton magnetic resonance spectroscopic imaging in newly diagnosed glioblastoma: predictive value for the site of postradiotherapy relapse in a prospective longitudinal study. Int J Radiat Oncol Biol Phys 2008;70:773-81.

[69] Thorwarth D, Henke G, Müller AC, Reimold M, Beyer T, Boss A, et al. Simultaneous 68Ga-DOTATOC-PET/MRI for IMRT treatment planning for meningioma: first experience. Int J Radiat Oncol Biol Phys 2011;81:277-83.

[70] Lambrecht M, Vandecaveye V, De Keyzer F, Roels S, Penninckx F, Van Cutsem E, et al. Value of diffusion-weighted magnetic resonance imaging for prediction and early assessment of response to neoadjuvant radiochemotherapy in rectal cancer: preliminary results. Int J Radiat Oncol Biol Phys 2012;82:863-70.

[71] Curvo-Semedo L, Lambregts DM, Maas M, Thywissen T, Mehsen RT, Lammering G, et al. Rectal cancer: assessment of complete response to preoperative combined radiation therapy with chemotherapy conventional MR volumetry versus diffusion-weighted MR imaging. Radiology 2011;260:734-43.

[72] Lambregts DM, Vandecaveye V, Barbaro B, Bakers FC, Lambrecht M, Maas M, et al. Diffusion-weighted MRI for selection of complete responders after chemoradiation for locally advanced rectal cancer: a multicenter study. Ann Surg Oncol 2011;18:2224-31.

[73] Mayr NA, Yuh WT, Magnotta VA, Ehrhardt JC, Wheeler JA, Sorosky JI, et al. Tumor perfusion studies using fast magnetic resonance imaging technique in advanced cervical cancer: a new noninvasive predictive assay. Int J Radiat Oncol Biol Phys 1996;36:623-33.

[74] Stewart J, Lim K, Kelly V, Xie J, Brock KK, Moseley J, et al. Automated weekly replanning for intensity-modulated radiotherapy of cervix cancer. Int J Radiat Oncol Biol Phys 2010;78:350-8.

[75] Lagendijk JJW, Raaymakers BW, Raaijmakers AJE, Overweg J, Brown KJ, Kerkhof EM, et al. MRI/linac integration. Radiother Oncol 2008;86:25-9.

[76] Raaymakers BW, Lagendijk JJW, Overweg J, Kok JGM, Raaijmakers AJE, Kerkhof EM, et al. Integrating a $1.5 \mathrm{~T}$ MRI scanner with a $6 \mathrm{MV}$ accelerator: proof of concept. Phys Med Biol 2009;54:N229-37.

[77] Raaymakers BW, Raaijmakers AJE, Lagendijk JJW. Feasibility of MRI guided proton therapy: magnetic field dose effects. Phys Med Biol 2008;53:5615-22.

[78] Dimopoulos JC, Schmid MP, Fidarova E, Berger D, Kirisits C, Pötter R. Treatment of locally advanced vaginal cancer with radiochemotherapy and magnetic resonance image-guided adaptive brachytherapy: dose-volume parameters and first clinical results. Int J Radiat Oncol Biol Phys 2012;82:1880-8. 